\title{
Struktur Pasar Komoditas Kentang Asal Batu di Malang Raya
}

Siti Risa Masyithoha, Rahayu Relawatia ${ }^{*}$, Gumoyo Mumpuni Ningsiha

aProdi Agribisnis, Fakultas Pertanian-Peternakan, Universitas Muhammadiyah Malang, Jawa TImur, Indonesia *Corresponding Author: rahayurelawati@umm.ac.id

\section{Article Info}

\section{Article history:}

Received 28 May 2021

Received in revised from 03 June 2021

Accepted 13 August 2021

DOI:

https://doi.org/10.32938/ag.v6i3.1376

Keywords:

Concentration Ratio

Herfindahl Hirschman Index

market share

market structure

\begin{abstract}
Abstrak
Potato production in Batu City, East Java, has increased but is not balance with the price stability received by farmers, due to market competition. This study purposed to analyze the structure of potato commodity market from Batu in Malang Raya (area includes Kota Malang, Kabupaten Malang, and Kota Batu). The sampling methods used were purposive sampling for determining potato farmers, and snowball sampling to determine traders along the marketing channel to follow the commodity flow of potato. The analysis of market structure includes market share, Concentration Ratio (CR4), and Herfindahl Hirchman Index. The results show that the market structure of potato commodities from Batu in Malang Raya is oligopoly market, which was identified from the market share, concentration ratio (CR) and Herfindahl Hirschman Index. The oligopoly market is known because the obtained CR4 value is between $20 \%-80 \%$ and the value of $\mathrm{IHH}>0.1$. In this market structure farmers have a low bargaining position, whose position is as price taker. The recommendation given to increase the bargaining position of farmers is to shorten the marketing channels, for example by guiding farmers to do online marketing, so that they can have direct access to the end consumer.
\end{abstract}

\section{Pendahuluan}

Kentang merupakan salah satu komoditas hortikultura penting karena banyak digunakan dalam konsumsi rumahtangga, menu hotel dan restoran, maupun sebagai bahan baku makanan ringan. Permintaan kentang meningkat seiring tumbuhnya Usaha Kecil dan Menengah (UKM) keripik kentang dan snack atau potato chips. Data statistik produksi sayuran di Jawa Timur tahun 2008-2017 menunjukkan bahwa salah satu sayuran yang cukup penting adalah kentang. Kentang menjadi salah satu komoditas unggulan nasional yang ada di Jawa Timur yang mampu menyumbangkan produksi sayuran nasional,selain bawang merah dan cabai rawit (BPS-JawaTimur. 2021).

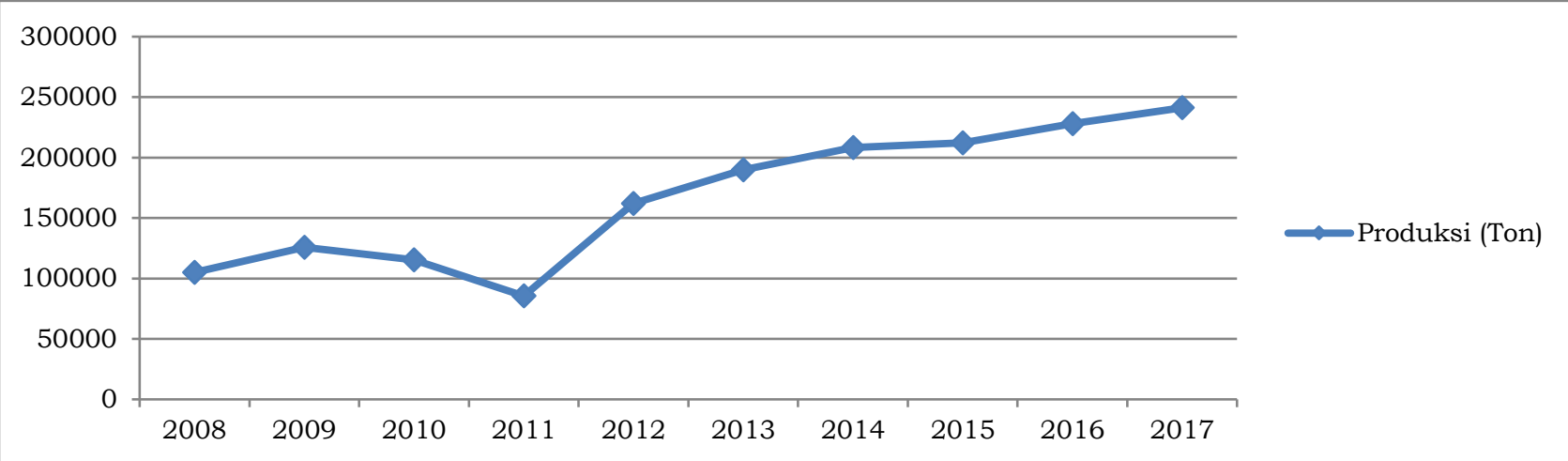

Grafik 1. Produksi kentang Provinsi Jawa Timur Tahun 2008-2017 (Ton) Sumber: BPS Jawa Timur (2021)

Pada periode tahun 2008-2017, kentang mengalami peningkatan produksi dari 125.886 Ton hingga 241.180 Ton (Grafik 1). Peningkatan produksi tersebut terjadi karena banyaknya petani yang membudidayakan kentang. Di beberapa tempat (Mauritius, Pangalengan, Bumiaji) kentang juga dibudidayakan sebagai adaptasi terhadap perubahan iklim untuk pemenuhan kebutuhan pangan (Ramlall, 2014; Sinaga, Fariyanti dan Tinaprilla, 2014). Akibatnya secara akumulatif terjadi peningkatan suplai kentang (Pujiharto dan Wahyuni, 2020), meskipun disisi konsumsi juga meningkat. Peningkatan produksi dan permintaan yang tidak sebanding dengan harga yang diterima oleh petani mempengaruhi struktur pasar kentang tersebut, sebagaimana juga terjadi pada pasar komoditi lain seperti cabai (Devi, Harsoyo dan Subejo, 2016).

Salah satu daerah penghasil dan pemasok kentang terbanyak di Jawa Timur adalah Kota Batu, karena berada di dataran tinggi dengan hawa yang sejuk sesuai untuk budidaya kentang. Kentang dari Kota Batu memasok kebutuhan kentang di luar Kota Batu (Anggraeni \& Baladina 
2017). Pasar kentang dari Batu meliputi wilayah Malang Raya (Kota Batu, Kota Malang, Kabupaten Malang), hingga ke wilayah Jawa Timur dan luar Jawa.

Struktur pasar menjadi ukuran yang sangat penting dalam melihat perilaku dan kinerja pasar. Pada beberapa tahun terakhir telah terjadi peningkatan permintaan dan harga pada kentang (Sinaga et al. 2014; Anggraeni \& Baladina 2017), akan tetapi peningkatan tersebut tidak berpengaruh terhadap posisi tawar petani kentang Batu. Lemahnya posisi tawar petani kentang juga diakibatkan oleh permainan harga struktur pasar tersebut (Sinaga et al. 2014).

Penelitian Sinaga et al.,(2014) menyatakan bahwa struktur pasar kentang Granola di Pangalengan Jawa Barat bersifat oligopsoni, terdiri dari sembilan saluran pemasaran, posisi petani sebagai penerima harga dan adanya hambatan masuk pasar karena peranan pedagang pengumpul. Kinerja pasar relatif efisien dengan nilai margin rata-rata sebesar $27,64 \%$ dan farmer share ratarata sebesar 72,36\%. Sementara itu penelitian Laibuni \& Omiti (2014) menyatakan bahwa pasar kentang di Kenya bersifat oligopolistik; beberapa pelaku pasar yakni tengkulak di pedesaan, grosir di perkotaan dan jasa pengangkutan memiliki kekuatan pasar;ada hambatan untuk masuk di pusat pasar perkotaan dimana broker menjadi perantara grosir dan pedagang pengecer.

Anggraeni dan Baladina (2017) menyatakan bahwa struktur pasar kentang di Desa Sumberbrantas mengarah ke pasar oligopoli, perilaku pasar kentang dimana terjadi kolusi dan petani bertindak sebagai price taker, dan kinerja pasar kentang menunjukkan bahwa share harga yang diterima petani lebih kecil dari harga yang dibayarkan konsumen. Posisi petani kentang sebagai price taker juga terjadi di Sumatera Utara (Sipayung \& Ginting 2019). Struktur pasar kentang di sentra produksi di Jawa Tengah adalah oligopsoni, dimana perilaku harga di tingkat petani (produsen) lebih dikendalikan oleh tengkulak, pembayaran dilakukan secara tunai atau dibayarkan kemudian (Pujiharto \& Wahyuni, 2020).

Penelitian dengan pendekatan Structure-Conduct-Performance (SCP) juga telah diterapkan pada berbagai komoditas pertanian yang lain. Agnellia et al. (2016) menganalisis SCP cabai di Desa Bayung Gede, Kecamatan Kintamani, dengan temuan bahwa struktur pasar cabai yang terbentuk adalah duopoli. Kinerja pasar yang dihasilkan adalah margin pemasaran saluran pertama adalah Rp 3.000 dengan pangsa petani sebesar 86,96\% dan efisiensi pemasaran sebesar 3,38\%. Margin pemasaran saluran kedua adalah Rp 5.000 dengan pangsa petani sebesar $80 \%$ dan efisiensi pemasaran sebesar 7,15\%.Margin pemasaran saluran ketiga adalah Rp 15.000 dengan pangsa petani $57,14 \%$ dan efisiensi pemasaran $8,32 \%$.

Beberapa penelitian terdahulu menunjukkan bahwa struktur pasar komoditi pertanian cenderung oligopoli dan ada pihak yang mempunyai posisi tawar paling kuat. Struktur pasar apel lokal di Malang Raya adalah oligopoli, dimana grosir mempunyai kekuatan tawar menawar paling kuat dan menikmati keuntungan pemasaran yang paling besar (Relawati et al. 2018). Struktur pasar beras di Kabupaten Siak adalah pasar oligopsoni, dimana petani menjadi price taker, dan keuntungan paling banyak diperoleh oleh pedagang yang melakukan lebih banyak fungsi pemasaran (Dewi et al., 2018). Demikian struktur pasar kopi di Ethiopia bersifat oligopoli, ditandai dengan hambatan masuk yang tinggi, diferensiasi produk dan strategi harga lebih ditentukan oleh pedagang (Kelifa, 2019). Industri benih jagung di Thailand bersifat oligopolistik, dimana bisnis perusahaan multinasional besar memiliki kekuatan pasar yang lebih kuat daripada yang lokal (Napasintuwong, 2020).

Beberapa penelitian terdahulu tentang struktur pasar kentang dan komoditi pertanian lain hampir semua menggunakan pendekatan SCP. Namun di antara berbagai penelitian tersebut belum ada yang mengintegrasikan data sekunder untuk menghitung struktur pasar kentang, selain menggunakan data primer untuk menghitung Concentration Ratio dan Herfindahl Hirchman Index (HHI). Perbedaan prinsip penelitian ini dengan penelitian Anggraeni dan Baladina (2017) adalah pada pembatasan hanya pada analisis struktur pasar dan pengintegrasian data primer dengan data sekunder untuk menghitung pangsa pasar kentang asal Desa Sumberbrantas.

Penelitian ini difokuskan pada analisis struktur pasar kentang. Kebaruan penelitian ini adalah mengintegrasikan data sekunder untuk menghitung struktur pasar kentang, selain menggunakan pendekatan Concentration Ratio dan Herfndahl Hirchman Index (HHI). Penelitian ini bertujuan untuk (1) menganalisis pangsa pasar komoditas kentang asal Batu di Malang Raya, (2) menganalisis struktur pasar komoditas kentang asal Batu di Malang Raya diukur dari rasio konsentrasi, (3) menganalisis struktur pasar komoditas kentang asal Batu di Malang Raya diukur dari Indeks Herfindahl Hirschman.

\section{Metode}

Penelitian dilakukan pada Bulan Januari hingga Maret 2019 di Kota Batu dan Kabupaten Malang. Lokasi penelitian tersebut dipilih karena merupakan penghasil produksi kentang terbesar di Malang Raya. Penentuan sampel petani dilakukan dengan purposive sampling, dengan kriteria petani kentang terbesar berdasarkan luas lahan, dan pada bulan terakhir saat pengambilan data 
penelitian panen dan memasarkan kentang ke pedagang setempat. Jumlah sampel petani sebanyak 20 orang. Penentuan sampel pedagang menggunakan snowball sampling, yakni mengikuti aliran komoditi kentang dari petani dipasarkan ke tengkulak atau langsung ke grosir, grosir pasar tradisional, dan pengecer di pasar tradisional di Malang Raya. Jumlah sampel pedagang adalah pedagang pengumpul 3 orang, grosir 10 orang, pedagang besar di pasar 4 orang, dan pedagang pengecer 10 orang. Jumlah seluruh sampel sebanyak 47 orang dari berbagai kategori pelaku agribisnis kentang.

Data primer diperoleh melalui wawancara berdasarkan kuesioner. Data sekunder berupa data BPS Kota Batu, data Kependudukan dan Catatan Sipil Kota Batu, data Balitbangda Kabupaten Malang, profil Desa Sumberbrantas, dan data produksi kentang dari Dinas Pertanian Kota Batu. Teknik analisis data meliputi: 1) analisis pangsa pasar; 2) Rasio Konsentrasi 4 (Concentration Ratio = CR4); dan 3) Indeks Herfindahl Hirschman. Perhitungan pangsa pasar (Market Share) dari produsen kentang asal Batu pada suatu pasar digunakan langkah perhitungan pada Tabel 1. Teknik perhitungan menggunakan alat bantu software MS Excel.

Tabel 1. Perhitungan Pangsa Pasar

\begin{tabular}{ccc}
\hline Pedagang kentang & Kapasitas produk (Ton) & Pangsa Pasar (\%) \\
\hline 1 & $\mathrm{~A}$ & $\mathrm{~A} / \mathrm{Xx} 100 \%$ \\
2 & $\mathrm{~B}$ & $\mathrm{~B} / \mathrm{Xx} 100 \%$ \\
3 & $\mathrm{C}$ & $\mathrm{C} / \mathrm{Xx} 100 \%$ \\
- & - & - \\
$\mathrm{n}$ & $\mathrm{Ni}$ & $\mathrm{n} / \mathrm{Xx} 100 \%$ \\
\hline Total & $\mathrm{A}+\mathrm{B}+\mathrm{C}+\mathrm{D}+\ldots .+\mathrm{ni}=\mathrm{X}$ & $100 \%$ \\
\hline
\end{tabular}

Pengukuran CR4 diambil dengan menjumlahkan empat pangsa pasar kentang terbesar, yang dapat dihitung dengan rumus: $\mathrm{CR} 4=\mathrm{S} 1+\mathrm{S} 2+\mathrm{S} 3+\mathrm{S} 4$

Dimana:

CR4 = Concentration Ratio $4(\%)$

$\mathrm{S} 1 ; \mathrm{S} 2 ; \mathrm{S} 3 ; \mathrm{S} 4=$ market share dari empat pedagang paling besar pada masing-masing kategori (\%)

Indeks Herfindahl dapat diperoleh berdasarkan rumus:

$\mathrm{IHH}=\left(\frac{\mathrm{Si}_{1}}{\mathrm{TSi}}\right)^{2}+\left(\frac{\mathrm{Si}_{2}}{\mathrm{TSi}}\right)^{2}+\left(\frac{\mathrm{Si}_{3}}{\mathrm{TSi}}\right)^{2}+\cdots+\left(\frac{\mathrm{Si}_{\mathrm{n}}}{\mathrm{TSi}}\right)^{2}$

IHH = Indeks Herfindahl Hirchman

$\mathrm{Si} \quad=$ volume pemasaran pedagang $\mathrm{ke}$ i (ton)

$\mathrm{TSi}=$ total volume pemasaran (ton)

Kriteria IHH:

a. Jika IHH $=1$ maka pasar kentang asal Batu mengarah pada pasar monopoli

b. Jika IHH $=0$ maka pasar kentang asal Batu mengarah pada pasar persaingan sempurna

c. Jika $0<\mathrm{IHH}<1$ maka pasar kentang asal Batu mengarah pada pasar oligopoli.

Software yang digunakan dalam perhitungan adalah MS Excel. Setiap tahap perhitungan indicator menggunakan rumus yang disajikan yang diintegrasikan dalam teknik formulasi pada software tersebut.

\section{Hasil dan Pembahasan}

Hasil penelitian yang disajikan meliputi; karakteristik petani dan pedagang kentang, pangsa pasar komoditas kentang di Malang Raya, serta hasil analisis CR4 dan IHH. Masing-masing hasil analisis dibahas dengan interpretasi, konfirmasi teori, dan verifikasi hasil dengan penelitian terdahulu.

\section{Pangsa Pasar Komoditas Kentang Asal Batu di Malang Raya}

Pangsa pasar petani kentang asal Batu dihitung dari sampel petani kentang terbesar di Desa Sumberbrantas, sejumlah 20 orang petani pada luas lahan 0,5 ha sampai paling terbesar 22 ha. Pangsa pasar petani dan pedagang kentang asal Batu disajikan pada Tabel 2.

Pangsa pasar dihitung pada berbagai level pelaku pasar, yakni petani, pedagang pengumpul, grosir, pedagang besar, dan pedagang pengecer. Dasar perhitungan pangsa pasar adalah volume produksi kentang di Malang Raya yang diperoleh dari data sekunder dari Dinas Pertanian selama empat bulan. Data sekunder selama empat bulan tersebut setara dengan satu musim tanam kentang dari petani. Data produksi kentang adalah data bulan September-Desember 2018, yakni yang tersedia terakhir sebelum pengambilan data primer pada awal tahun 2019 . 
Tabel 2. Pangsa Pasar Kentang asal Batu pada Berbagai Pelaku Pasar di Malang Raya

\begin{tabular}{lccc}
\hline \multicolumn{1}{c}{ Pelaku pasar } & $\begin{array}{c}\text { Volume pemasaran } \\
\text { pedagang (Ton) }\end{array}$ & $\begin{array}{c}\text { Volume total kentang di } \\
\text { pasar (Ton)* }\end{array}$ & Pangsa pasar (\%) \\
\hline Petani & $1.575,0$ & & 52,88 \\
Pedagang pengumpul & 350 & $2.978,6$ & 11,75 \\
Pedagang grosir/besar & $2.978,6$ & 100,0 \\
Pedagang pengecer & 288 & 9,67 \\
\hline
\end{tabular}

*Volume dihitung berdasarkan produksi kentang selama empat bulan (September-Desember 2018) dari data sekunder, hasilnya mendekati volume pemasaran pedagang besar yang merupakan jumlah total volume pemasaran kentang di Malang Raya.

Sumber: Analisis data primer tahun 2019, dan sekunder tahun 2018.

Tabel 2 menunjukkan hasil pangsa pasar petani adalah 52,88\% dari volume produksi yang dipasarkan di Malang Raya. Artinya jumlah produksi kentang petani responden di Desa Sumberbrantas mencapai pangsa pasar pada angka tersebut di Malang Raya. Jumlah persentase sisanya $(47,12 \%)$ disuplai dari petani desa tersebut yang tidak menjadi responden penelitian, dan dari sumber desa lain atau dari Kabupaten lain. Informasi lapang menjelaskan bahwa pedagang juga memasarkan kentang dari lereng Gunung Bromo. Kekurangan suplai kentang pada suatu waktu mendorong pedagang membeli kentang tidak hanya di sekitar daerahnya, sehingga saluran pemasaran kentang menjadi cukup panjang (Sinaga et al., 2014).

Nilai pangsa pasar petani kentang asal Batu tersebut cukup tinggi, dimana tingginya pangsa pasar tersebut memberikan kekuatan pasar kentang yang besar di dalam suatu pasar. Di pasar Malang Raya terdapat juga kentang dari daerah lain, namun kentang asal Batu tetap mampu bersaing dan unggul. Bagi pedagang, level konsentrasi pasar akan mempengaruhi persaingan antar pelaku pasar (Mu'azu et al., 2013). Kentang asal Batu memiliki kualitas dan kuantitas yang tinggi, produktivitas kentang mencapai 20 Ton/Ha. Saat penelitian harga kentang yang diterima petani berkisar dari Rp 10.000 sampai Rp 12.500 per Kg.

Hasil perhitungan pangsa pasar pada pedagang pengumpul dan pedagang pengecer menunjukkan nilai pangsa pasar masing-masing sebesar 11,75\% dan 9,67\%. Artinya pedagang pengumpul dan pedagang pengecer yang menjadi responden penelitian hanya merupakan sebagian kecil dari pelaku pasar pada level tersebut. Jumlah pedagang kategori tersebut sangat banyak, dengan volume pemasaran yang relatif kecil.

Pangsa pasar pada pedagang grosir dan pedagang besar mencapai $100 \%$, artinya pedagang kentang di Malang Raya menyerap penjualan sebanyak 100\% dari pasar kentang di Malang Raya. Ada sedikit selisih perhitungan volume pemasaran antara data primer dan data sekunder, namun selisih tersebut dalam kategori pembulatan data. Pangsa pasar berkisar antara 0 hingga $100 \%$, demikian juga semakin tinggi pangsa pasar CR maka semakin tinggi pula kekuatan pasar yang dimiliki oleh pelaku pasar (Raha et al., 2013; Nzima et al., 2014), termasuk pedagang kentang asal Batu. Makin rendah nilai $\mathrm{CR}$ maka semakin rendah kekuatan pasar para pedagang atau pelaku pasar.

\section{Struktur Pasar Komoditas Kentang Berdasarkan Rasio Konsentrasi}

Struktur pasar pada komoditas kentang asal Batu tidak hanya dapat dilihat dari pangsa pasar, akan tetapi juga dari nilai rasio konsentrasi (CR). Rasio Konsentrasi empat (CR4) dapat dilihat dengan menjumlahkan pangsa pasar empat terbesar dari setiap pelaku pasar (mulai dari petani hingga pedagang pengecer).

Pangsa pasar dari keempat pelaku pasar tersebut dapat digunakan untuk mengetahui pasar terkonsentrasi kearah pasar persaingan sempurna atau pasar persaingan tidak sempurna. Jika diketahui nilai tingkat CR tinggi, maka tingkat persaingan di dalam pasar tersebut rendah. Sebaliknya jika CR rendah berarti persaingan pasar kentang tinggi (Nzima et al., 2014; Sayaka, 2006). Hasil perhitungan nilai CR komoditas kentang asal Batu disajikan pada Tabel 3. 
Tabel 3. Perhitungan Rasio Konsentrasi 4 (CR4) Petani dan Pedagang Kentang di Malang Raya

\begin{tabular}{|c|c|c|c|}
\hline $\begin{array}{l}\text { Pelaku pasar dan satuan } \\
\text { volume }\end{array}$ & $\begin{array}{c}\text { Volume pemasaran } \\
4 \text { terbesar }\end{array}$ & Pangsa pasar (\%) & $\begin{array}{c}\text { Nilai kuadrat dari } \\
\text { market share* }\end{array}$ \\
\hline $\begin{array}{r}\text { Petani (Ton) } \\
\\
\text { Total CR4 } \\
\end{array}$ & $\begin{array}{l}550 \\
220 \\
105 \\
100\end{array}$ & $\begin{array}{c}34,92 \\
13,97 \\
6,67 \\
6,35 \\
\mathbf{6 1 , 9 1} \\
\end{array}$ & $\begin{array}{l}0,1219 \\
0,0195 \\
0,0044 \\
0,0040\end{array}$ \\
\hline $\begin{array}{c}\text { Pedagang Pengumpul (Ton) } \\
\text { Total CR4 } \\
\end{array}$ & $\begin{array}{c}180 \\
90 \\
80\end{array}$ & $\begin{array}{c}50,00 \\
26,92 \\
23,08 \\
\mathbf{1 0 0 , 0 0} \\
\end{array}$ & $\begin{array}{l}0.2500 \\
0.0725 \\
0.0533\end{array}$ \\
\hline $\begin{array}{c}\text { Pedagang Grosir (Ton) } \\
\text { Total CR4 } \\
\end{array}$ & $\begin{array}{l}900 \\
420 \\
248 \\
220\end{array}$ & $\begin{array}{c}32,63 \\
14,66 \\
8,99 \\
8,86 \\
\mathbf{6 5 , 1 4}\end{array}$ & $\begin{array}{l}0,1065 \\
0,0215 \\
0,0081 \\
0,0079\end{array}$ \\
\hline Pedagang besar (Ton) & $\begin{array}{l}450 \\
400 \\
300 \\
280\end{array}$ & $\begin{array}{c}31,47 \\
27,97 \\
20,98 \\
19,58 \\
\mathbf{1 0 0 , 0 0}\end{array}$ & $\begin{array}{l}0,0990 \\
0,0782 \\
0,0440 \\
0,0383\end{array}$ \\
\hline Total CR4 & $\begin{array}{l}60 \\
60 \\
45 \\
30\end{array}$ & $\begin{array}{l}20,83 \\
20,83 \\
15,63 \\
10,42 \\
\mathbf{6 7 , 7 1}\end{array}$ & $\begin{array}{l}0,0434 \\
0,0434 \\
0,0244 \\
0,0109\end{array}$ \\
\hline
\end{tabular}

*Nilai kuadrat dari market share masing-masing petani atau pedagang, jumlah totalnya adalah IHH; Sumber: Analisis data primer, 2019

Berdasarkan Tabel 3, hasil perhitungan CR4 menunjukkan bahwa empat petani kentang terbesar asal Batu mempunyai pangsa pasar 61,91\%. Artinya nilai produksi kentang asal Batu dari 4 petani terbesar mencapai $61,91 \%$ dari total produksi kentang. Hal tersebut menunjukkan bahwa sebanyak 61,91\% pangsa pasar dikuasai oleh 4 petani kentang terbesar. Apabila terdapat empat petani atau pedagang yang menguasai pasar antara 20\% sampai $80 \%$ termasuk ke dalam struktur pasar yang bersaing dan mengarah pada pasar oligopoli.

Pasar oligopoli kentang pada petani kentang asal Batu dapat diketahui termasuk ke dalam pasar oligopoli ketat karena nilai CR4 yang diperoleh berada pada $60 \%-100 \%$. Pernyataan ini sesuai dengan syarat yang dikemukakan oleh Jaya (2001) yang menyatakan bahwa jika penggabungan 4 perusahaan memiliki nilai pangsa pasar antara 60\%-100\%, maka termasuk ke dalam oligopoli (Rizkyanti, 2010). Akhirnya konsentrasi pasar ini juga akan mempengaruhi efisiensi pasar (Shaik et al., 2009). Pasar oligopoli yang ada pada petani kentang asal Batu menunjukkan bahwa kemiripan antar sesama petani dalam pasar sangat kecil, sehingga keberadaan petani dalam suatu pasar akan memiliki lebih banyak pilihan untuk mengimplimentasikan strategi dan persaingan yang sehat antar petani.

Konsentrasi Rasio pada pelaku pasar yaitu pedagang kentang asal Batu diperoleh hasil nilai konsentrasi rasio dari penjualan 4 pedagang terbesar terdapat pada pedagang grosir, pedagang besar, dan pengecer. Hasil konsentrasi rasio (CR4) pada empat volume penjualan terbesar pedagang grosir, pedagang pengumpul, edagang besar, dan pengecer kentang asal Batu terbesar di Malang Raya dapat diketahui bahwa struktur pasar kentang asal Batu di Malang Raya pada tingkat pedagang mengarah ke pasar oligopoli karena nilai CR4 berada di antara $20 \%-80 \%$.

\section{Struktur Pasar Kentang Asal Batu Berdasarkan Indeks Herfindahl Hirschman}

Struktur pasar kentang asal Batu dapat diukur dan ditinjau tidak hanya berdasarkan nilai pangsa pasar dan konsentrasi rasio (CR) saja, akan tetapi terdapat pengukuran struktur pasar lain yang digunakan yaitu Indeks Herfindahl Hirschman (IHH). IHH digunakan untuk mengukur kekuatan pasar pada komoditas kentang asal Batu dalam struktur pasar. Apabila telah diketahui bagaimana kekuatan penentu pasar pada kentang asal Batu, maka akan dengan mudah suatu pedagang maupun produsen (petani) untuk melakukan tawar menawar terhadap pembeli. IHH 
struktur pasar kentang diukur dari penjumlahan pangkat dua nilai pangsa pasar setiap pelaku dibagi total pangsa pasar keseluruhan yang telah diperoleh pada pembahasan sebelumnya. Hasil dari perhitungan nilai IHH disajikan pada Tabel 4.

Tabel 4. Perhitungan Indeks Herfindahl Hirschman Pelaku Pasar Kentang Asal Batu di Malang Raya

\begin{tabular}{lr}
\hline \multicolumn{1}{c}{ Pelaku pasar } & Indeks Herfindahl Hirschman* \\
\hline Petani & 0.1715 \\
Pedagang Pengumpul & 0.7515 \\
Pedagang Grosir & 0.1258 \\
Pengecer & 0.1447 \\
\hline
\end{tabular}

*dihitung dari jumlah total dari nilai kuadrat market share seluruh responden

Sumber: Analisis data primer, 2019

Tabel 4 menunjukkan hasil perhitungan Indeks Herfindahl Hirschman pada produksi kentang di level petani, dimana total nilai IHH adalah 0,1715. Nilai IHH tersebut berada lebih dari 0 dan kurang dari 1, maka struktur pasar kentang asal Batu mengarah ke pasar oligopoli. Konsentrasi pasar oligopoli pada petani kentang asal Batu mengarah ke konsentrasi sedang karena nilai IHH sudah melewati batas indeks persaingan yakni 0,1 (Nzima et al., 2014; Anggraeni \& Baladina 2017). Hasil perhitungan Indeks Herfindahl Hirschman pedagang kentang asal Batu di Malang Raya dapat teridentifikasi jenis pasar pada setiap pedagang kentang asal Batu yaitu bahwa dari tingkat pedagang pengumpul, pedagang grosir, dan pengecer menunjukkan bahwa struktur pasar kentang asal Batu di Malang Raya mengarah ke pasar oligopoli, karena nilai IHH berada antara $0-1$. Konsentrasi pasar oligopoli setiap pedagang kentang asal Batu di Malang Raya mengarah ke konsentrasi sedang hingga tinggi. Menurut Nzima et al.,(2014) jika nilai IHH >0,1 maka pasar sudah melewati batas kategorikan pasar persaingan, berarti mengarah ke oligopoli.

Pada pasar oligopoli, posisi tawar petani paling lemah karena petani menjadi penerima harga (price taker) dari pedagang tengkulak dan grosir (Anggraeni \& Baladina 2017; Sipayung \& Ginting 2019). Oleh karena itu posisi tawar petani dalam pemasaran kentang perlu ditingkatkan. Sebagai solusi digital marketing, atau pemasaran kentang berdasarkan teknologi digital perlu diperkenalkan dan diimplementasikan di tingkat petani. Digital marketing secara konseptual dapat mengefisienkan pemasaran dan mengurangi margin harga antara harga petani dengan harga pengecer (Bhosage, 2018; Juswadi et al., 2020).

\section{Simpulan}

Pangsa pasar komoditas kentang asal Batu sebesar 52,88\% dari volume produksi yang dipasarkan di Malang Raya. Struktur pasar komoditas kentang asal Batu di Malang Raya diukur dari rasio konsentrasi (CR4) adalah oligopoli, dengan CR4 pada berbagai pelaku pasar berkisar antara $61,9 \%$ hingga $76,9 \%$ atau berada pada kisaran $40 \%$ hingga $80 \%$. Secara konsisten struktur pasar kentang diukur dari IHH juga menunjukkan kategori oligopoli, yakni dengan kisaran 0,1258 hingga 0,3757 pada berbagai level pelaku pasar. Pada struktur pasar oligopoli, petani sebagai pelaku pasar yang paling banyak memiliki posisi tawar yang paling rendah, karena menjadi penerima harga (price taker) dari pedagang tengkulak hingga grosir.

Rekomendasi yang diberikan untuk menaikkan posisi tawar petani adalah dengan memperpendek saluran pemasaran, misalnya dengan pembinaan petani untuk melakukan pemasaran secara online, sehingga mereka dapat mempunyai akses langsung pada konsumen akhir. Penelitian lanjutan yang perlu dilakukan adalah menganalisis struktur pasar secara lengkap dengan pendekatan struktur-perilaku-kinerja pasar kentang dan analisis pemasaran kentang secara digital.

\section{Pustaka}

Agnellia, M.A.D.D., Ustriyana, I.N.G. \& Djelantik, A.A.. W.S., 2016. Analisis Struktur, Perilaku, Dan Kinerja Pasar Cabai di Desa Bayung Gede, Kecamatan Kintamani, Kabupaten Bangli. EJournal Agribisnis dan Agrowisata, 5(1), pp.1-10. Available at: https://ocs.unud.ac.id/index.php/JAA/article/view/18660.

Anggraeni, M.D. \& Baladina, N., 2017. Analisis Struktur, Perilaku dan Penampilan Pasar Kentang di Desa Sumberbrantas, Kecamatan Bumiaji, Kota Batu. Jurnal Ekonomi Pertanian dan Agribisnis (JEPA), $\quad \mathrm{I}(2), \quad$ pp.69-79. Available at: https://jepa.ub.ac.id/index.php/jepa/article/view/11/12.

Bhosage, S.M., 2018. E-Marketing of Agricultural Products. In International Conference on Digital Economy and its Impact on Business and Industry. pp. 70-73.

BPS-Prov.Jawa-Timur, 2021. Produksi Sayuran dan Buah-buahan Semusim di Jawa Timur Tahun 


\section{8-2017, \\ Badan \\ Pusat \\ Statistik. \\ Available}

at:

https:/ /jatim.bps.go.id/statictable/2018/11/06/1374/produksi-sayuran-dan-buahbuahan-semusim-di-jawa-timur-ton-2008-2017.html.

Devi, P., Harsoyo, H. \& Subejo, S., 2016. Keefektifan Lembaga Pasar Lelang Cabai Merah Di Kecamatan Panjatan Kabupaten Kulon Progo. Agro Ekonomi, 26(2), pp.139-149. Available at: https://journal.ugm.ac.id/jae/article/view/17273.

Dewi, N., Yusri, J. \& Saputra, A.J., 2018. Analisis Struktur Perilaku dan Kinerja Pasar (Structure, Conduct and Market Performan) Komoditi Padi di Desa Bunga Raya dan Desa Kemuning Muda Kecamatan Bunga Raya Kabupaten Siak. Jurnal Agribisnis, 19(1), pp.42-56. Available at: http://journal.unilak.ac.id/index.php/agr/article/view/897.

Juswadi, J., Sumarna, P. \& Mulyati, N.S., 2020. Digital Marketing Strategy of Indonesian Agricultural Products. In Advances in Social Science, Education and Humanities Research. pp. 105-110. Available at: https://www.mendeley.com/catalogue/9207c78b-1dae-3d61-93d9$749 \mathrm{~d} 2 \mathrm{e} 30 \mathrm{~b} 5 \mathrm{f} 2 /$.

Kelifa, A., 2019. Review on Structure-Conduct-Performance of Coffee Market in Ethiopia. Food Science and Quality Management, 86, pp.28-34. Available at: https://www.mendeley.com/catalogue/afd50316-7cfa-34d0-aa79-9242b562ba33/.

Laibuni, N. \& Omiti, J., 2014. Market Structure and Price: An empirical analysis of Irish potato markets in Kenya. International Journal of Research in Marketing, 2(3), pp.47-50. Available at: https: / / www.mendeley.com/catalogue/f2621983-6c11-31cc-af9e-3c6d44de6b4e/ Market.

Mu'azu, A.U. et al., 2013. Structure-Conduct-Performance of the Malaysian Poultry Industry. Australian Journal of Basic and Applied Sciences, 7(8), pp.170-177.

Napasintuwong, O., 2020. Thailand's maize seed market structure, conduct, performance. Future of Food: Journal on Food, Agriculture and Society, 8(2 (June)), pp.1-15. Available at: https://www.mendeley.com/catalogue/38d34a66-b426-3577-991f-64027fdb5614/.

Nzima, W.M., Dzanja, J. \& Kamwana, B., 2014. Structure, Conduct and Performance of Groundnuts Markets in Northern and Central Malawi: Case Studies of Mzimba and Kasungu Districts. International Journal of Business and Social Science, 5(6).

Pujiharto, P. \& Wahyuni, S., 2020. Potato Trading Based on Structure Conduct Performance (SCP) in the Centre of Vegetable Production at Central Java Indonesia. Research in World Economy, 11(1 (Special Issue)), pp.171-179. Available https://www.mendeley.com/catalogue/7f7f5fd8-ec7b-377b-9dad-f644ae76cfbd/.

Raha, S.K. et al., 2013. Structure, Conduct and Performance of the Rice Market and the Impact of Technological Changes in Milling, Mymensingh: Institute of Agribusiness and Development Studies (IADS) Bangladesh Agricultural University.

Ramlall, I., 2014. Gauging the impact of climate change on food crops production in Mauritius An econometric approach. International Journal of Climate Change Strategies and Management, 6(3), pp.332-355.

Relawati, R. et al., 2018. The Structure-Conduct-Performance of Indonesian Apple Fruit Market. In Advance in Engineering Research, 4th International Converence on Food and Agriculture Resources (Fanres 2018). pp. 239-244.

Rizkyanti, A., 2010. Analisis Struktur Pasar Industri Karet dan Barang Karet Periode Tahun 2009. Media Ekonomi, 18(2), Av.1-18. Available at: http://www.trijurnal.lemlit.trisakti.ac.id/index.php/medek/article/view/54/52.

Sayaka, B., 2006. Market structure of the corn seed industry in East Java. Journal Agro Ekonomi, 24(2), pp.133-156.

Shaik, S. et al., 2009. Market Structure Conduct Performance Hypothesis Revisited Using Stochastic Frontier Efficiency Analysis. Agribusiness \& Applied Economics 649, 48(September).

Sinaga, V.R., Fariyanti, A. \& Tinaprilla, N., 2014. Analisis Struktur, Perilaku, dan Kinerja Pemasaran Kentang Granola di Kecamatan Pangalengan, Kabupaten Bandung, Jawa Barat. Forum Agribisnis, 4(2), pp.101-120. Available at: https://www.mendeley.com/catalogue/afdaba14-79da-3ef6-ad0b-25a9e0b9c27e/.

Sipayung, B.P. \& Ginting, R., 2019. Analisis Faktor Penawaran Kentang di Provinsi Sumatera Utara (Periode 2003-2012). Agrimor, 4(1), pp.7-8. Available at: https://savanacendana.id/index.php/AG/article/view/692/290. 